Gazi University
Journal of Science
$\mathrm{http} / /$ dergipark.gov.tr/gujs

\title{
The Effects of Diflubenzuron on Acetylcholinesterase (EC 3.1.1.7) Activity and Liver Ultrastructure in Wistar Rats
}

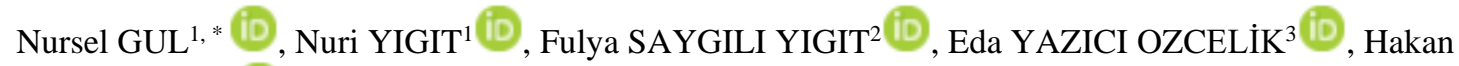 \\ ESKIZENGIN $^{1}$ \\ ${ }^{I}$ Department of Biology, Faculty of Science, Ankara University, Ankara, 06100, Turkey \\ ${ }^{2}$ Department of Biotechnology, Faculty of Arts and Sciences, Niğde Ömer Halisdemir University, Niğde, 51240, Turkey \\ ${ }^{3}$ Department of Medical Microbiology, Institute of Health Sciences, Kocaeli University, Kocaeli, 41380, Turkey
}

\section{Highlights}

- This article focuses on the effects of diflubenzuron on AChE activity of rat liver.

- Diflubenzuron is also harmful to some non-target organisms.

- This study will be able to guide research on biocidal products.

\begin{tabular}{l} 
Article Info \\
\hline $\begin{array}{l}\text { Received: } 16 \text { Feb } 2021 \\
\text { Accepted: } 12 \text { Jan } 2022\end{array}$ \\
Keywords \\
\hline $\begin{array}{l}\text { Diflubenzuron } \\
\text { Rat } \\
\text { Liver ultrastructure } \\
\text { Acetylcholinesterase } \\
\text { enzymatic activity }\end{array}$
\end{tabular}

\begin{abstract}
Diflubenzuron is a commonly used larvicide/biocidal substance. The present study aimed to reveal the effects of diflubenzuron on Acetylcholinesterase (AChE) enzymatic activity and liver histopathology of a mammalian species (rats). The animals fed with various doses of diflubenzuron and the liver tissues of rats were taken on the 10th, 20th, 25th, 45th days and sixth month. AChE activity of liver was measured by spectrophotometer. Tissues were embedded in Araldite 502 (Sigma), took ultrathin sections, and examined under a 100 CX II Transmission Electron Microscope. AChE activity in the chronic dose of diflubenzuron group was like that in the control group. The enzymatic activity in the subacute dose was found to be significantly different from the control group. After subacute dose exposure was terminated, the AChE activity was still lower on the 45th day compared with the control group. Chronic and subacute doses caused adverse effects to liver tissues, such as numerous mitochondria, abnormally structured nuclei in the hepatocytes and many lipid droplets in the sinusoids of the liver ultrastructure. After the subacute dose was terminated, liver damage was still observed on the 20th and 25th days, but the liver tissue was partly regenerated on the 45 th day. Cellular damage might recover after 45 days, but AChE activity probably takes more time to reach a normal level.
\end{abstract}

\section{INTRODUCTION}

Insecticides are pesticides that are formulated to kill, harm, repel or mitigate one or more species of insects [1-3], and they are commonly used to protect against insects in households, restaurants, hospitals, farms, warehouses, etc. These substances are also important for preventing insect-borne diseases [4-6]. Highly effective insecticides act on targets specific to nerves, muscles, liver structure, and oxidative stress [7-13]. The insecticide IGR (insect growth regulator), which is thought to have minimal effects on the environment and non-target organisms, has been used in the control of insects [14]. For this reason, these substances are widely used in water sources such as sewage, lakes, ponds, and rivers [15]. World Health Organization (WHO) recommended that dosage of diflubenzuron in potable water in containers should not exceed 0.25 $\mathrm{mg} / \mathrm{l}$ [16]. Diflubenzuron (a well-known IGR) has been reported to have a more harmful effect on mosquito larvae and less of an effect on non-target organisms such as aquatic organisms, bees, fish, reptiles, birds, and mammals [12, 17-19].

Most of the biocidal products are cholinesterase inhibitory [20,21], especially the organophosphates and the carbamates, which show strong anti-cholinesterase activity by inactivating both acetylcholinesterase 
and butyrylcholinesterase [22]. There are some reports that diflubenzuron shows similar effects on AChE enzymatic activity levels compared to organophosphate and carbamate groups [23, 24].

A dose of $25 \mathrm{mg}$ of diflubenzuron was applied to freshwater fish (Prochilodus lineatus), and it was determined that this dose decreased the muscle AChE enzymatic activity level in the fish. The $\mathrm{LC}_{50}$ dose was reported that caused a $44 \%$ decrease and the $\mathrm{LC}_{90}$ dose $55 \%$ decrease in the AChE enzyme activity level of mosquitofish (Gambusia affinis) [23]. However, there is no available record about the effect of diflubenzuron on mammalian AChE enzymatic activity levels. It is also unknown exactly what kind of damage is caused to mammalian tissues by random environmental exposure.

An adverse effect of diflubenzuron on the liver structure of Swiss Webster mice was reported by observing hepatocellular vacuolization between the portal and central area via light microscopy and increased rough endoplasmic reticulum (RER) organelles in the hepatocytes by Transmission Electron Microscope [25]. The effects of Curacron (profenofos), Sumicidin (fenvalerate), and Diflubenzuron (Dimilin) on the liver and muscles of rabbits were determined by RNA and protein synthesis in vitro [26]. According to the results, the synthesis of these molecules was induced in the liver, whereas they were inhibited in the muscles, and diflubenzuron was reported to have a maximum effect on the liver and muscle tissue among the insecticides used.

Therefore, the present study aimed to reveal the effect of diflubenzuron on AChE enzymatic activity and liver histopathology in Wistar rats.

\section{MATERIAL METHOD}

Adult male rats (Wistar albino, 7-9 weeks old, 200-230 g body weight) were used in this study after ethical approval from The Local Ethics Committee (Decision No: 2015-18-134) on Animal Experiments of Ankara University. Animals were quarantined for seven days before experiments [27]. All animals were sacrificed under ether anestesia. The animals (total: 36 individuals) were divided into 6 groups:

1) Control group rats: Peanut butter was given daily to the control group and then sacrificed after 10 days,

2) Second group rats (Subacute dose group) ( $25 \mathrm{mg} / \mathrm{kg} / \mathrm{day}$ dose): Diflubenzuron in peanut butter was given to rats and after 10 days they were sacrificed,

3) Third group rats ( $25 \mathrm{mg} / \mathrm{kg} / \mathrm{day} / \mathrm{dose})$ : Diflubenzuron in peanut butter was given to rats and after 20 days they were sacrificed,

4) Fourth group rats $(25 \mathrm{mg} / \mathrm{kg} / \mathrm{day}$ dose): Diflubenzuron in peanut butter was given to rats and after 25 days they were sacrificed,

5) Fifth group rats (subchronic dose) $(25 \mathrm{mg} / \mathrm{kg} /$ day dose): Diflubenzuron in peanut butter was given to rats and after 45 days they were sacrificed,

6) Sixth group rats (Chronic dose group) $(25 \mathrm{mg} / \mathrm{kg} / \mathrm{day}$ dose): Diflubenzuron in peanut butter was given to rats for six months.

The acetylcholinesterase (EC 3.1.1.7) enzymatic activity of rats was measured according to the Ellman procedure [28]. Six measurements were performed every 30 seconds for this solution with a spectrophotometer (Bio Drop Touch Duo Biochrom LTD, USA) at a wavelength of $405 \mathrm{~nm}$. The measurements were applied to the formula [differences between the readings $\times 23.460=$ result $(\mathrm{u} / \mathrm{l})$ ], and according to this formula, the enzymatic activity was detected. The activity measurements were analysed by ANOVA (one-way ANOVA). Liver tissue samples of the rats were excised carefully and fixed with $2.5 \%$ glutaraldehyde in $0.1 \mathrm{M}$ sodium phosphate buffer $(\mathrm{pH} 7.2)$ and postfixed in $1 \%$ osmium tetraoxide solution. Fixed tissues were dehydrated and embedded in Araldite 502 (SIGMA) [29]. Ultrathin sections were examined under a 100 CX II Transmission Electron Microscope (JEOL, Tokyo, Japan) at $80 \mathrm{kV}$, and all images were acquired using a side-inserted camera (EMSIS Veleta, Germany) from the Biology Department, Faculty of Science, Ankara University. Chemicals for electron microscopy were purchased from Electron Microscopy Sciences (EMS). 


\section{RESULTS}

Diflubenzuron is one of the most used insect growth regulators applied in every kind of aquatic system, (clear water, pond, and sewage), to for larvae management. It is thought to be harmless to non-target animals such as mammals. For this purpose, the effects of diflubenzuron on the AChE enzymatic activity and liver histopathology in mammals were investigated using rat blood and liver tissues, respectively. AChE enzymatic activity was measured to vary from $563 \mathrm{u} / \mathrm{ml}$ to $586.5 \mathrm{u} / \mathrm{ml}$ in the control group of rats. Two different doses (chronic and subacute doses) were given to rats to determine the effect on AChE enzymatic activity. The first dose was $25 \mathrm{mg} / \mathrm{kg}$ diflubenzuron, which was added to rat food and was consumed for 10 days by the rats. This dose is considered as a subacute dose due to the $\mathrm{LD}_{50}$ value $(4.64 \mathrm{~g} / \mathrm{kg})$. Then, the AChE enzymatic activity was measured in the blood samples (n: 6). The AChE enzymatic activity values (n: 6) were found in the range of $258 \mathrm{u} / \mathrm{ml}$ to $351.9 \mathrm{u} / \mathrm{ml}$ with an average value of $305 \mathrm{u} / \mathrm{ml}$. These values were found to be statistically significant compared to the control group $(\mathrm{P}<0.05)$. Measurements of $\mathrm{AChE}$ enzymatic activity were performed on the 10th, 25th, and 45th days. The results showed that the values of AChE enzymatic activity were still markedly lower (average $307.3 \mathrm{u} / \mathrm{ml}$ ) than the control group after 45 days of exposure. The AChE enzymatic activity was determined to be between $586.5 \mathrm{u} / \mathrm{ml}$ and $656.9 \mathrm{u} / \mathrm{ml}$ in the chronic dose group rats. These values were not statistically significant from the control group by ANOVA ( $\mathrm{P}>0.05)$. However, the rats exposed to chronic doses showed some morphological signs, such as skin redness, hair loss, eye irritation, and movement difficulty, after 6 months.

We examined the liver ultrastructure of the control and diflubenzuron-exposed groups to reveal the effects of diflubenzuron. In the control group rats, the liver had normal ultrastructures, such as hepatocytes with oval-shaped nuclei, rough endoplasmic reticulum (RER) cisternae, same-sized mitochondria and the regular sinusoidal area shapes (Figure 1).

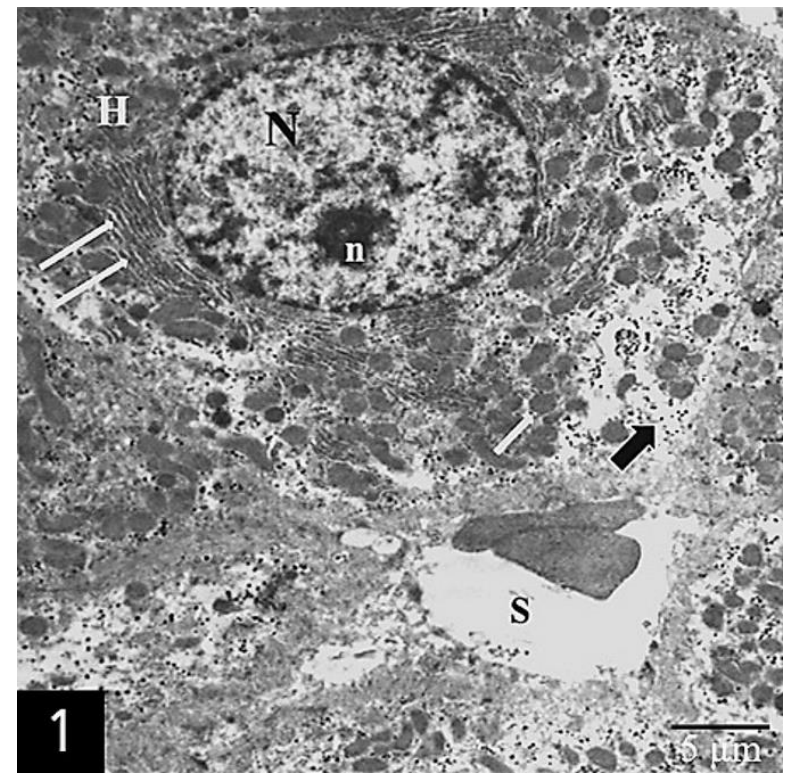

Figure 1. Liver of control group rats with hepatocytes $(H)$ and sinusoidal area $(S)$. Rough Endoplasmic Reticulum (double white arrow), Mitochondrium (white arrow), Nucleus (N), Nucleolus (n), Glycogen

(black arrow). X 5200

It was observed that hepatocytes contained large/small mitochondria that contacted each and invaginations of the nuclear envelope (Figure 2a). There were different cells (erythrocytes, Kupffer cells), cellular residue, and accumulation of condensed material in the sinusoidal area of the rat livers of the second group (subacute dose group). Additionally, around the sinusoidal area, the hepatocytes had enlarged RER cisternae organelles (Figure $2 b$ ). These organelles may synthesis enzymes for the elimination of the adverse effects of diflubenzuron. 


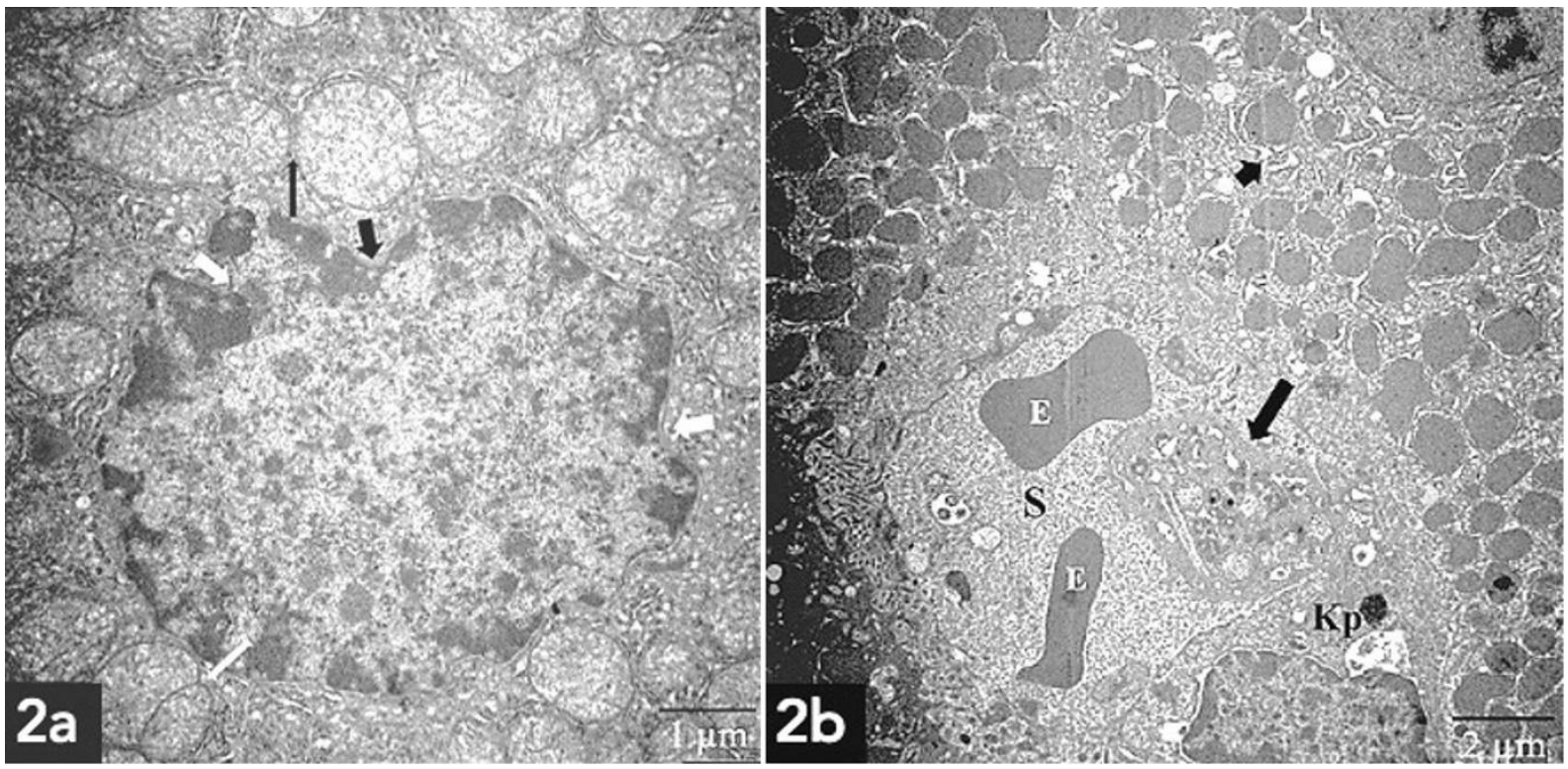

Figure 2. (a) The liver hepatocyte of second group rat micrograph showed that there were contact each other mitochondria (thin arrow) and invagination of nuclear envelope (thick arrow). X. 15000 (b) Kupffer cell (Kp), irregular shape Erythrocytes (E) and cellular residue (arrow) in the sinusoidal area $(S)$ and hepatocytes with enlarged RER cisternae (arrowhead) were seen in the liver of second group rats. $X 8000$

The third group (after 20 days diflubenzuron administrated) rat livers had detrimental structural effects caused by diflubenzuron. For example, the hepatocytes had numerous lysosomes, and the sinusoidal area of the rat livers had a few erythrocytes (Figure 3a). Hepatocytes had numerous vacuole organelles (these vacuoles may be mitochondria with melted cristae) as a sign of disorder in cellular structure. Cellular residue, lipid droplets, and Kupffer cells were seen in the sinusoidal area of the rat livers (Figure $3 b$ ).



Figure 3. (a) The hepatocyte with lysosome organelles (arrows) and nucleus (N), and there are erythrocytes $(E)$ in the sinusoidal area of third group rats liver. X. $6000(\boldsymbol{b})$ The livers had hepatocyte with numerous vacuole organelles $(V)$ and sinusoidal area with cellular residue (arrow), Kupffer cell $(K p)$, erythrocytes (E), lipid droplets $(L)$. X 8000

The fourth group ( 25 days after diflubenzuron administrated) rat livers showed abnormal ultrastructure. For example, the RER of the hepatocytes were numerous and enlarged and placed around the nucleus, probably because the organelles synthesized an enzyme against diflubenzuron toxicity. Additionally, this cell had 
lysosomes and mitochondria that each contacted and placed among the RER. The nucleus of these cells had abnormal ultrastructures, such as the invagination of the nuclear envelope and an irregular shape (Figure 4).

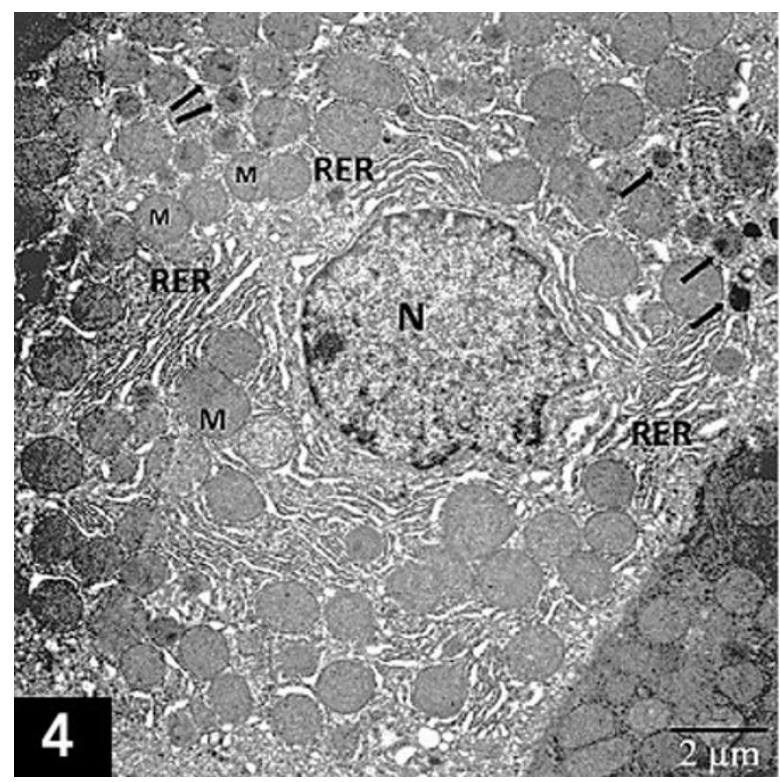

Figure 4. Enlarged RER cisternae (RER), lysosomes (arrows), each contacted to mitochondria $(M)$ and ondulated shape of nucleus $(N)$ in liver hepatocyte of fourth group rat. X 10000

The hepatocytes of the fifth group (45 days after diflubenzuron administrated, subchronic dose group) rat livers had a polygonal pattern completely free from the effects of diflubenzuron (Figure $5 a$ ). Besides, the hepatocytes of this group of rat livers had an enlarged RER and mitochondria among the RER (Figure $5 b$ ).
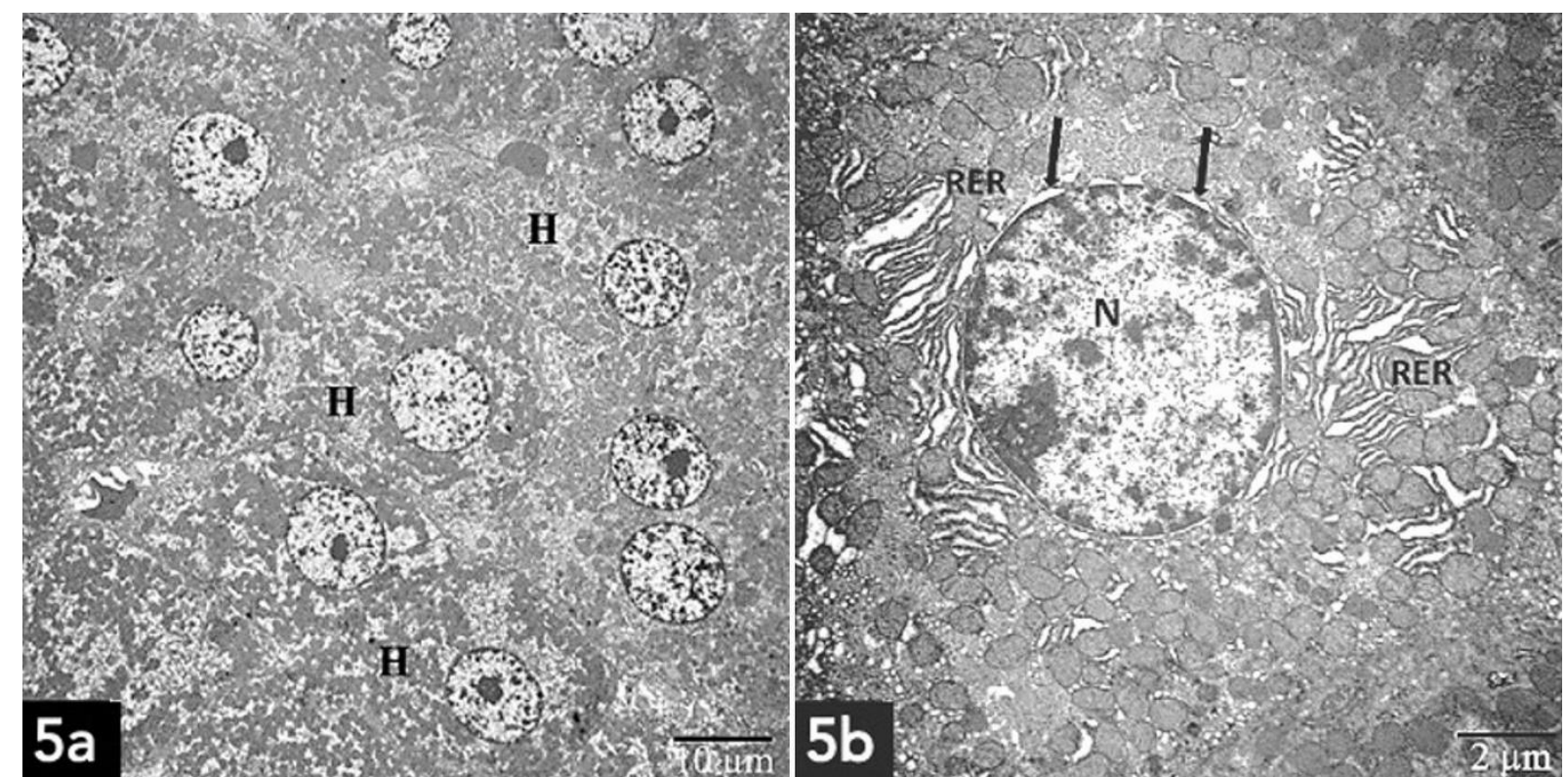

Figure 5. (a) Liver hepatocyte cells $(H)$ were lined up properly and these cells had normal ultrastructural morphology as a sign of healing. X. 15000 (b) A lot of enlarged rough endoplasmic reticulum (RER) cisternae and nucleus $(N)$ with enlarged perinuclear space (arrows) in active liver hepatocyte of the subcronic dose group rats. $X 8000$

The liver sections of the sixth group (chronic dose of diflubenzuron rats group) showed that numerous mitochondrium in their hepatocytes. In sinusoidal areas of these group rats, the formation of lipid droplets was seen connecting, which is thought to be due to the toxic effects of diflubenzuron. Numerous lipid droplets were seen in the sinusoidal area, and Kupffer cells phagocyted these lipid droplets (Figure 6a). 
Kupffer and neutrophil cells were seen together in the sinusoidal area of the liver. It was thought that these cells pinocyted the toxic material diflubenzuron (Figure $6 b$ ).

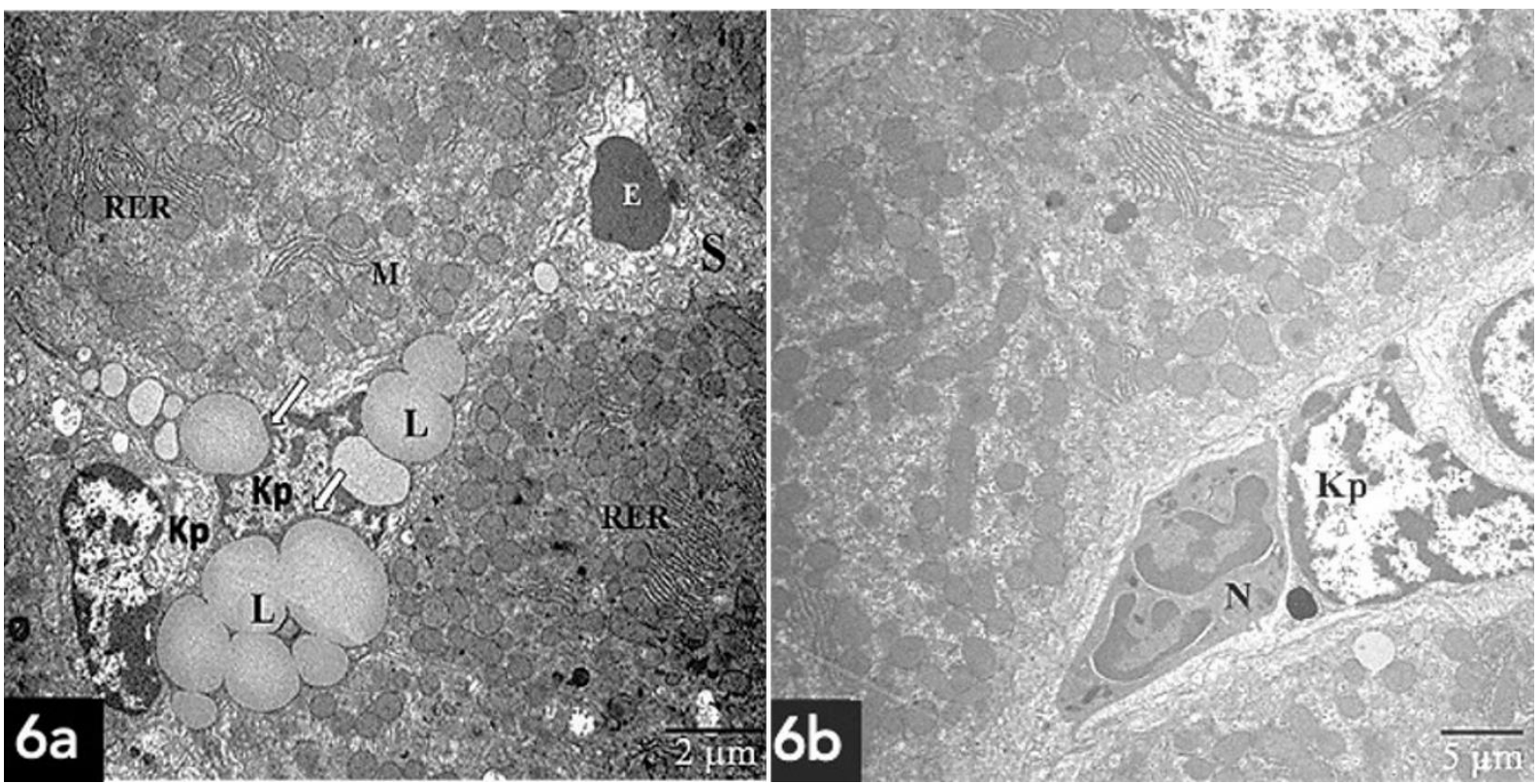

Figure 6. (a) Lipid droplets connect to each other $(L)$, erythrocyte $(E)$ and phagocytosis (arrows) of lipid droplets by Kupffer cells $(K p)$ in sinusoidal area $(S)$, RER and mitochondrium $(M)$ in the hepatocytes. $X$. 6000 (b) Kupffer cells (Kp) and neutrophil cell $(N)$ in sinusoidal area liver of chronic dose of diflubenzuron rat group. $X 7200$

In the liver sections of rats exposed to a chronic dose of diflubenzuron, some cytological signs to eliminate the toxicity of diflubenzuron were seen; as signs of immunity to diflubenzuron toxicity, an increase in lysosomes in the Kupffer cell in the sinusoidal area, and many RER cisternae in the hepatocytes were observed by transmission electron microscope (Figure 7).

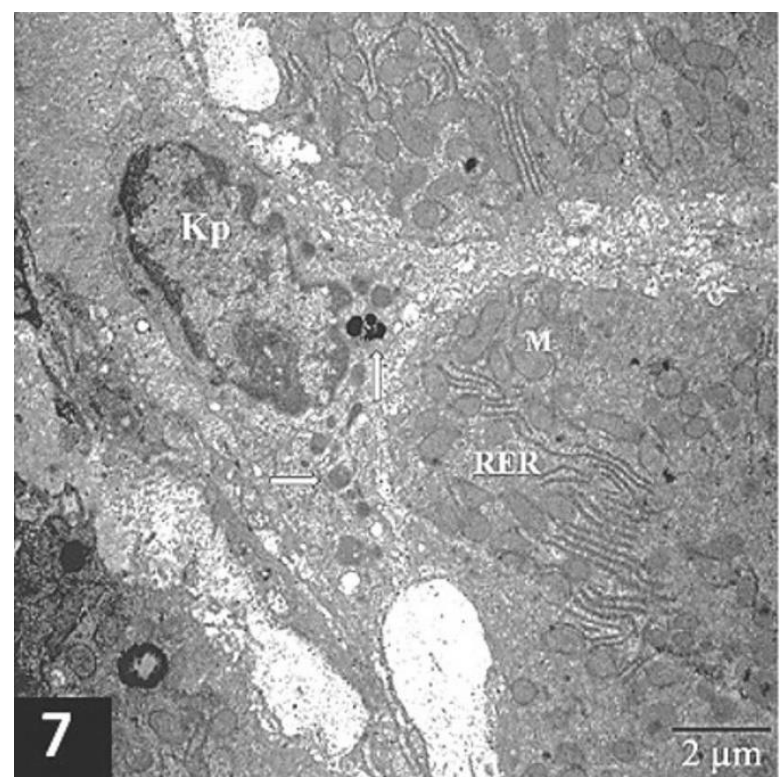

Figure 7. Kupffer cell (Kp) with lysosomes organelles (arrows) and active hepatocytes with numerous rough endoplasmic reticulum (RER) organelles in the liver results from chronic dose of diflubenzuron. 


\section{DISCUSSION}

In this study, the effect of diflubenzuron, an insecticide, on liver cell structure and AChE enzyme of rats was investigated. The liver is a major organ where toxic substances are eliminated. It is known that insecticides (organochlorine, organophosphate, and carbamate groups) inhibit the AChE enzyme activity [20,30-34]. Dieldrin (an organochlorine insecticide) was reported that reduced AChE enzyme activity in the brain of Mus booduga [35]. Similarly, we detected that subacute doses of diflubenzuron reduced the AChE enzymatic activity in rats.

The effect of cyanophos (organophosphate group) on the activities of the enzymes AChE, aspartate transaminase (AST), alanine transaminase (ALT), and alkaline phosphatase (ALP) of rats was investigated, and it was observed that AChE enzyme activity was inhibited at the end of the third day, and no recovery occurred by the end of the 15th day [36]. Our findings reveal that chronic exposure had no effect on AChE enzyme activity, but subacute exposure caused an approximately $43 \%$ reduction in acetylcholinesterase enzymatic activity in rats.

The acute effects of diflubenzuron on muscle AChE activity, detoxification, antioxidant enzymes, hematological and physiological parameters, and liver histopathology of the freshwater fish Prochilodus lineatus were studied [23]. It was reported that the muscle AChE enzymatic activity of freshwater fish decreased after 6, 24, and 96 hours of diflubenzuron exposure. Additionally, the levels of erythrocytes and hemoglobin decreased at the end of 96 hours, whereas the nuclei and cellular densities, cytoplasm, and nucleus degenerations increased. These findings from fish supported our results indicating sub-acute doses reduce the AChE enzymatic activity in rats.

Different doses $(125,500$, and $2000 \mathrm{mg} / \mathrm{kg}$ body weight) of diflubenzuron were reported that caused an increased number of swelled mitochondria, decreased matrix density, and increased RER in the liver [25]. In our study, subacute dose, 20 and 25 days after of diflubenzuron caused a large number RER and mitochondria in the hepatocytes. Kupffer cells, lipid droplets, and erythrocytes were also found in the sinusoidal area.

Ulusoy et al. [37] examined the effect of diazinon on rat hepatocytes under electron microscopy. At the end of various application periods of diazinon in rat liver, pycnotic nuclei formation in hepatocytes, loss of material in cytoplasm and increased volume in mitochondria were observed. In our study, similar findings were found at subacute dose.

The effects of different doses of Permethrin, a pyrethroid-derived insecticide, on mouse liver and spleen cells were investigated. It has been reported that Permethrin causes shrinkage of nuclei in the hepatocytes of mice and the formation of waste material in the cytoplasm and proliferation of Kupffer cells in the space of disse [38]. In this study, it was determined that subacute dose of diflubenzuron caused degeneration and increase of Kupffer cells in rat liver hepatocytes.

Atlantic cod (Gadus morhua) were exposed to diflubenzuron and teflubenzuron to kill its parasite (Lepeophtheirus salmonis). Researchers applied low doses (3 mg kg-1 fish) of diflubenzuron to Atlantic cod for 14 days followed by a 3-week depuration period. The strongest effects were observed on day 8 , and the highest diflubenzuron concentrations were found in the liver on day 15 [39]. We observed that a subacute dose ( $25 \mathrm{mg} / \mathrm{kg}$ for 10 days) of diflubenzuron affected liver hepatocyte structure with increased mitochondria, nuclear degeneration and Kupffer cells with lysosome organelles in the liver sinusoidal area. Liver damage lasted 10 days after termination of the exposure processes, but after 25 and 45 days, the livers began to heal.

The effect of diflubenzuron on nontarget animals by applying $0,2,4$ and $8 \mathrm{mg} / \mathrm{kg}$ doses of diflubenzuron to adult male rats was investigated. The sub-acute doses of diflubenzuron affected rats differently. Sperm morphology, epididymis, liver, and kidney histology showed no abnormal structures, while testicular weight and sperm production decreased in the rats [40]. Our results from a sub-acute dose showed that diflubenzuron is harmful in many ways to the cell ultrastructures of the rat livers. 
The findings for example infiltration, vacuolisation, enlarged sinusoids, and necrosis are seen in female albino rats administrated to triazophos [41]. Some histological damages in livers of fish and rats exposed to sub-lethal doses of diazinon for a long time were reported $[9,42]$. The observations of authors were such as damage in Disse's space and necrosis, changes in nuclear shape, heterochromatin distribution of hepatocytes in the liver of organisms. Effects of Dimethoate on rats' liver were examined in light microscope, the author was reported a histopathological change such as mononuclear cell infiltration, many Kupffer cells and dilatation in sinusoids of liver and necrosis, cytoplasmic vacuolisation, and degeneration of nuclei in hepatocyte of rat livers [43]. Subacute and chronic doses of organophosphorus pesticides were reported that they had harmful effects on the liver structure in various organisms [44]. In this study, we observed same histopathological findings such as numerous Kupffer cells in sinusoidal area, necrosis, cytoplasmic vacuolisation, degeneration of nuclei in hepatocytes of rat livers administrated acute doses of diflubenzuron. When a chronic dose of diflubenzuron was applied to rats, and no morphological changes were observed in the liver structure, but the hepatocytes had increased mitochondria and RER organelles as signs of the presence of diflubenzuron.

This study revealed that a subacute dose of diflubenzuron affected serum AChE enzyme activity and liver histopathology in rats, whereas chronic doses of diflubenzuron had no effect on AChE activity or liver histopathology. It could be said that our study, along with references, will be able to guide research on biocidal products, which are thought to be less harmful to non-target organisms.

\section{CONFLICTS OF INTEREST}

No conflict of interest was declared by the authors.

\section{REFERENCES}

[1] Silva, A. X., Jander, G., Samaniego, H., Ramsey, J.S., Figueroa, C.C., “ Insecticide resistance mechanisms in the green peach aphid Myzus persicae (Hemiptera: Aphididae) I: a transcriptomic survey”, PloS One, 7(6): p.e36366, (2012). DOI:10.1371/journal.pone.0036366

[2] Casida, J.E., Durkin, K.A., "Pesticide chemical research in toxicology:lessons from nature", Chemical Research in Toxicology, 30: 94-104, (2017). DOI: 10.1021/acs.chemrestox.6b00303

[3] Saleh, T.A., Ahmed, K.S., El-Bermawy, S.M., Ismail, E.H., Abdel-Gawad, M., "Histological and ultrastructural aspects of larval corpus allatum of Spodoptera littoralis (Boisd.) (Lepidoptera: Noctuidae) treated with diflubenzuron and chromafenozide", Journal of Entomology and Zoology Studies, 6: 864-872, (2018).

[4] Hoffman, D.J., Rattner, B.A., Burton, Jr G.A., Cairns, Jr J., Handbook of Ecotoxicology, CRC Press LLC Lewis Publishers, Boca Raton, FL, (2003).

[5] Meissle, M., Mouron, P., Musa, T., Bigler, F., Pons, X., Vasileiadis, V.P., Otto, S., Antichi, D., Kiss, J., Pálinkás, Z., Dorner, Z., "Pests, pesticide use and alternative options in European maize production: current status and future prospects", Journal of Applied Entomolology, 134: 357-375, (2010). https://doi.org/10.1111/j.1439-0418.2009.01491.x

[6] Clasen, B., Loro, V.L., Murussi, C.R., Tiecher, T.L, Moraes, B., Zanella, R., "Bioaccumulation and oxidative stress caused by pesticides in Cyprinus carpio reared in a rice-fish system", The Science of the Total Environment, 626: 737-743, (2018). DOI: 10.1016/j.scitotenv.2018.01.154

[7] Bloomquist, J.R., "Ion channels as targets for insecticides", Annual Review of Entomology, 41: 163-190, (1996). DOI:10.1146/annurev.en.41.010196.001115

[8] Grosicka-Maciąg, E.,"Biological consequences of oxidative stress induced by pesticides", Postepy Higieny i Medycyny Doswiadczalnej(Online), 65: 57-366, (2011). DOI: 10.5604/17322693.948816 
[9] Banaee, M., Sureda, A., Mirvaghefi, A.R., Ahmadi, K.J.F., "Biochemical and histological changes in the liver tissue of rainbow trout (Oncorhynchus mykiss) exposed to sub-lethal concentrations of diazinon", Fish Physiology and Biochemistry, 39: 489-501, (2013). DOI: 10.1007/s10695-012-97141

[10] Casida, J.E., Durkin, K.A., "Neuroactive insecticides: targets, selectivity, resistance, and secondary effects", Annual Review of Entomology, 58: 99-117, (2013). DOI: 10.1146/annurev-ento-120811153645

[11] Beydilli, H., Yılmaz, N., Çetin, E.S., Topal, Y., Çelik, O.İ., Şahin, C., Topal, H., Ciğerci, I.H., Sözen, H.,"Evaluation of the protective effect of silibinin against diazinon induced hepatotoxicity and freeradical damage in rat liver", Iranian Red Crescent medical journal, 17: e25310, (2015). DOI: 10.5812/ircmj.17(4)2015.25310

[12] Nesterov, A., Spalthoff, C., Kandasamy, R., Katana, R., Rankl, N.B., Andrés, M., Jähde, P., Dorsch, J.A., Stam, L.F., Braun, F.J., Warren, B., "TRP channels in insect stretch receptors as insecticide targets", Neuron, 86: 665-671, (2015). DOI: 10.1016/j.neuron.2015.04.001

[13] Dantzger, D.D., Jonsson, C.M., Aoyama, H., "Mixtures of diflubenzuron and p-chloroaniline changes the activities of enzymes biomarkers on tilapia fish (Oreochromis niloticus) in the presence and absence of soil", Ecotoxicology and Environmental Safety, 148: 367-376, (2018). DOI: 10.1016/j.ecoenv.2017.10.054

[14] World Health Organization (WHO): Diflubenzuron in drinking-water: use for vector control in drinking-water sources and containers. World Health Organization, WHO Press, Geneva, (2008).

[15] Muzinic, V., Zeljezic, D., "Non-target toxicity of novel insecticides", Arhiv za Higijenu Rada i Toksikologiju, 69: 86-102, (2018). DOI: 10.2478/aiht-2018-69-3111

[16] World Health Organization (WHO) Guidelines for Drinking-Water Quality, 3rd Edition including 1st and 2nd addenda, 2008.

[17] Castro, A.A., Lacerda, M.C., Zanuncio, M.C., Ramalho, F.S., Polanczyk, R., Serrão, J.E., Zanuncio, J.C., "Effect of the insect growth regulator diflubenzuron on the predator Podisus nigrispinus (Heteroptera: Pentatomidae)", Ecotoxicology, 21: 96-103, (2011). DOI: 10.1007/s10646-011-0769$\mathrm{Z}$

[18] Chang, J., Wang, H., Xu, P., Guo, B., Li, J., Wang, Y., Li, W., "Oral and dermal diflubenzuron exposure causes a hypothalamic-pituitary-thyroid (HPT) axis disturbance in the Mongolian racerunner (Eremias argus)", Environmental Pollution, 232: 338-346, (2018). DOI: 10.1016/j.envpol.2017.08.115

[19] World Health Organization (WHO): WHO Specifications and Evaluations for Public Health Pesticides: Diflubenzuron 1-(-4 chlorophenyl)-3-(2,4-difluorobenzoyl) urea. FAO/WHO Evaluation Report on Diflubenzuron, (2006).

[20] Mason, H.J., Sams, C., Stevenson, A.J., Rawbone, R., "Rates of spontaneous reactivation and aging of acetyicholinesterase in human erythrocytes after inhibition by organophosphorus pesticides", Human \& Experimental Toxicology, 19: 511-516, (2000). DOI: 10.1191/096032700667340089

[21] Habes, D., Morakchi, S., Aribi, N., Farine, J.P., Soltani, N., "Boric acid toxicity to the German cockroach, Blattella germanica: Alterations in midgut structure, and acetylcholinesterase and glutathione S-transferase activity", Pesticide Biochemistry and Physiology, 84: 17-24, (2006). https://doi.org/10.1016/j.pestbp.2005.05.002 
[22] Kim, Y.B., Hur, G.H., Shin, S., Sok, D.E., Kang, J.K., Lee, Y.S., “Organophosphate-induced brain injuries: delayed apoptosis mediated by nitric oxide", Environmental Toxicology and Pharmacology, 7: 147-152, (1999). DOI: 10.1016/s1382-6689(99)00006-x

[23] Maduenho, L.P., Martinez, C.B., "Acute effects of diflubenzuron on the freshwater fish Prochilodus lineatus", Comparative Biochemistry and Physiology, Toxicology \& Pharmacology, 148: 265-272, (2008). DOI: 10.1016/j.cbpc.2008.06.010

[24] Zaidi, N., Soltani, N., "Laboratory evaluation of environmental risk assessment of pesticides for mosquito control: toxicity of dimilin on a larvivorous fish, Gambusia affinis", Advances in Environmental Biology, 7(4): 605-613, (2013).

[25] Young, M.F., Trombetta, L.D., Carson, S., "Effects of diflubenzuron on the mouse liver", Journal of Applied Toxicology, 6: 343-348, (1986). DOI: 10.1002/jat.2550060508

[26] El-Sebae, A.H., Salem, M.H., El-Assar, M.R.S., Enan, E.E., "In vitro effect of profenofos, fenvalerate and dimilin on protein and RNA biosynthesis by rabbit liver and muscle tissues", Journal of environmental science and health, Part B, Pesticides, food contaminants, and agricultural wastes, 23: 439-451, (1988). DOI: 10.1080/03601238809372618

[27] Hadler, M.R., Buckle, A.P., "Forty-five years of anticoagulant rodenticides - past, present and future trends". In: Borrecco JE, Marsh RE, (editors), Proceedings of the Fifteenth Vertebrate Pest Conference; 3-5 March 1992, University of California, Newport Beach, California, Davis, 149-155, (1992).

[28] Ellman, G.L., Courtney, K.D., Andres, Jr V., Featherstone, R.M., "A new and rapid colorimetric determination of acetylcholinesterase activity", Biochemical Pharmacology, 7: 88-95, (1961). DOI: 10.1016/0006-2952(61)90145-9

[29] Hayat, M.A., Principles and techniques of electron microscopy, Biological applications, Second Edition, Volume 1, University Park Press, Baltimore, MD, (1981).

[30] Wilson, B. Cholinesterases. In: Krieger, R., Editor, Hayes Handbook Of Pesticide Toxicology, Third Edition, 1457-1478, London, (2010).

[31] Smulders, C. J., Bueters, T. J., Vailati, S., van Kleef, R. G., Vijverberg, H. P., "Block of Neuronal Nicotinic Acetylcholine Receptors by Organophosphate Insecticides", Toxicological Sciences : an official journal of the Society of Toxicology, 82,545-554, (2004). https://doi.org/10.1093/toxsci/kfh269

[32] Karami-Mohajeri, S., Abdollahi, M., "Toxic influence of organophosphate, carbamate, and organochlorine pesticides on cellular metabolism of lipids, proteins, and carbohydrates: a systematic review", Human \& Experimental Toxicology, 30: 1119-1140, (2011). DOI: $10.1177 / 0960327110388959$

[33] Lee, S., Barron, M.G., “ A mechanism-based 3D-QSAR approach for classification and prediction of acetylcholinesterase inhibitory potency of organophosphate and carbamate analogs", Journal Of Computer-Aided Molecular Design, 30: 347-363, (2016). DOI: 10.1007/s10822-016-9910-7

[34] Lu, J., Zhang, M., Lu, L., "Tissue metabolism, hematotoxicity, and hepatotoxicity of trichlorfon in Carassius auratus gibelio after a single oral administration", Frontiers in Physiology, 9: 551, (2018). DOI: 10.3389/fphys.2018.00551 
[35] Begum, S., Reddy, M.M., Indira, K., Swami, K.S., "Effect of dieldrin on catalytic potential of field mouse Mus booduga brain acetylcholinesterase", Archives internationales de physiologie et de biochimie, 95: 101-104, (1987). https://doi.org/10.3109/13813458709104521

[36] Afify, A.E.M.R., El-Beltagi, H.S., "Effect of the insecticide cyanophos on liver function in adult male rats", Fresenius Environmental Bulletin, 20: 1084-1088, (2011).

[37] Ulusoy, Y., Toprak, B., Uzunhisarcıkl1, M., Öğütçü, A., "Diazinonun Sıçan Hepatositleri Üzerine Etkisinin Elektron Mikroskobu İle İncelenmesi”, Etlik Veteriner Mikrobiyoloji Dergisi, 15(1-2): 2936, Ankara, (2004).

[38] Roma, G.C., De Oliveira, P.R., Bechara, G.H., Camargo Mathias M.I., "Cytotoxic Effects of Permethrin on Mouse Liver and Spleen Cells", Microscopy Research and Technique, 75: 229-238, Roma, (2012). DOI: 10.1002/jemt.21047

[39] Olsvik, P.A., Samuelsen, O.B., Erdal, A., Holmelid, B., Lunestad, B.T., "Toxicological assessment of the anti-salmon lice drug diflubenzuron on Atlantic cod Gadus morhua", Diseases of Aquatic Organisms, 105: 27-43, (2013). DOI: 10.3354/dao02613

[40] De Barros, A.L., Cavalheiro, G.F., De Souza, A.V., Traesel, G.K., Anselmo-Franci, J.A., Kassuya, C.A., Arena, A.C., "Subacute toxicity assessment of diflubenzuron, an insect growth regulator, in adult male rats", Environmental Toxicology, 31: 407-414, (2016). DOI: 10.1002/tox.22054

[41] Sharma, D., Sangha, G.K., "Triazophos induced oxidative stress and histomorphological changes in liver and kidney of female albino rats", Pesticide Biochemistry and Physiology, 110: 71-80, (2014). DOI: $10.1016 /$ j.pestbp.2014.03.003

[42] Zhuang, X.M., Wei, X., Tan, Y., Xiao, W.B., Yang, H.Y., Xie, J.W., Lu, C., Li, H., “Contribution of carboxylesterase and cytochrome P450 to the bioactivation and detoxification of isocarbophos and its enantiomers in human liver microsomes", Toxicological Sciences : an Official Journal of the Society of Toxicology, 140: 40-8, (2014). DOI: 10.1093/toxsci/kfu067

[43] Sayım, F., "Dimethoate-induced biochemical and histopathological changes in the liver of rats", Experimental and Toxicologic Pathology, 59: 237-43, (2007). DOI: 10.1016/j.etp.2007.05.008

[44] Karami-Mohajeri, S., Ahmadipour, A., Rahimi, H.R., Abdollahi, M., "Adverse effects of organophosphorus pesticides on the liver: a brief summary of four decades of research", Arhiv za higijenu rada i toksikologiju, 68: 261-275, (2017). DOI: 10.1515/aiht-2017-68-2989 